\title{
Universalização do acesso à internet dos estudantes brasileiros? 0 olhar de dois professores pesquisadores da educação básica
}

\author{
Universalization of internet access for brazilian students? The view of two \\ basic education teacher researchers
}

\section{¿Universalización del acceso a internet para estudiantes brasileños? La visión de dos profesores-investigadores de la educación básica}

William Souza Passos ${ }^{1}$

https://orcid.org/0000-0003-4648-121X

Humberto Salustriano da Silva²

https://orcid.org/0000-0001-5035-5510

\begin{abstract}
Resumo: Este artigo apresenta uma reflexão que confronta $\circ$ olhar de dois professores pesquisadores com mais de uma década de experiência na educação básica com parte dos resultados da pesquisa TIC Educação 2018 sobre $\circ$ uso das tecnologias de informação e comunicação nas escolas urbanas brasileiras. $O$ objetivo é o de provocar o debate acerca de necessidade de problematizar o impacto sobre os processos de ensinoaprendizagem ante o deslocamento improvisado e temporário de parte do ano letivo de 2020 para plataformas virtuais, em função da pandemia da Covid-19, assim como a importância da continuidade da utilização das tecnologias da informação e comunicação, mesmo após esse momento excepcional. Destaca-se, na reflexão, a utilização de Pierre Bourdieu e Regina Novaes como referências teóricas.
\end{abstract}

Palavras-chave: Acesso à Internet. Estudantes brasileiros. Educação básica.

Abstract: This article presents a reflection that confronts the view of two teacher researchers with more than a decade of experience in basic education with part of the results of ICT in Education 2018 research about the use of information and communication technologies in Brazilian urban schools. The objective is to provoke a

\footnotetext{
' Doutorando em Planejamento Urbano e Regional pelo Instituto de Pesquisa e Planejamento Urbano e Regional - IPPUR/UFRJ. Docente da rede municipal de educação de Quissamã - RJ. E-mail: geograwilliam@gmail.com

${ }^{2}$ Doutor em Educação pela UNIRIO- Universidade Federal do Estado do Rio de Janeiro. Docente da rede municipal de educação de Quissamã- RJ. E-mail: humbertosalustriano2005@yahoo.com.br
} 
debate about the need to problematize the impact on teaching-learning processes in the face of the improvised and temporary displacement of part of the 2020 school year to virtual platforms, in function of the COVID-19 pandemic, as well as the importance of the continuity of the use of information and communication technologies, even after this exceptional moment. In the reflection, the use of Pierre Bourdieu and Regina Novaes as theoretical references stands out.

Keywords: Internet access. Brazilian students. Basic education.

Resumen: En este artículo se presenta una reflexión que confronta la visión de dos professores investigadores con más de una década de experiencia en educación básica con parte de los resultados de la investigación TIC Educación 2018 sobre el uso de tecnologías de la información y la comunicación en escuelas urbanas brasileñas. El objetivo es suscitar un debate sobre la necesidad de problematizar el impacto en los processos de enseñanzaaprendizaje frente al desplazamiento improvisado y temporal de parte del año escolar 2020 a plataformas virtuales, debido a la pandemia COVID-19, así como la importancia de seguir utilizando las tecnologías de la información y la comunicación, incluso después de este momento excepcional. En la reflexión, se destaca el uso de Pierre Bourdieu y Regina Novaes como referencias teóricas.

Palabras-clave: Acceso a Internet. Estudiantes brasileños. Educación básica.

\section{Introdução}

O percentual de crianças e adolescentes brasileiros que acessam a Internet em ambiente escolar (apenas 30\%) é menor do que o encontrado em países vizinhos. Enquanto, por exemplo, 66\% dos estudantes do Chile fazem uso da rede na escola (CABELLO et al., 2018), segundo o relatório Kids On-line (UNICEF, 2018), cerca de 82\% conectam-se no Uruguai.

Uma explicação, segundo o relatório, que apresenta os resultados de uma pesquisa de acesso a TICs (tecnologias da informação e comunicação) no ambiente escolar de diferentes países da América Latina, pode estar no fato de, em geral, os estudantes brasileiros não poderem acessar a Internet pelo smartphone nos espaços escolares. Outro motivo pode residir justamente na falta de disponibilidade de acesso à rede, tendo em vista que em $66 \%$ das escolas urbanas a rede WiFi é bloqueada por senha e o acesso aos estudantes não é liberado.

Este cenário, associado às restrições de conexão derivadas das dificuldades de acesso à Internet no Brasil e limitadas pelo elevado custo do serviço e pelo baixo nível de renda da maioria da população, tem contribuído para ampliar as dificuldades de migração forçada para o ERE - Ensino Remoto Emergencial (HODGES et al., 2020) 3 durante a pandemia da Covid-19 no país, mais precisamente após a suspensão das aulas presenciais a partir de março de 2020. Nesse contexto, apresentando parte dos resultados da pesquisa TIC Educação 2018 (NIC.BR, 2019) - pesquisa sobre o uso das tecnologias de informação e comunicação nas escolas urbanas brasileiras - e partindo do olhar de dois professores pesquisadores com a experiência de mais de uma década na educação básica, a presente reflexão

\footnotetext{
${ }^{3}$ Holges et al. (2020) definem ERE como uma alternativa temporária de entrega de instruções escolares, em momentos emergenciais ou de crise, como a da pandemia da Covid-19, que envolve soluções de ensino completamente remotas em substituição àquelas que seriam ministradas presencialmente. Para os autores, o ERE, pelo seu caráter predominantemente síncrono, diferencia-se da Educação à Distância (EaD), que se caracteriza por atividades totalmente assíncronas.
} 
pretende provocar o debate acerca da necessidade de problematizar o impacto sobre os processos de ensino-aprendizagem ante o deslocamento improvisado e temporário de parte do ano letivo de 2020 para plataformas virtuais, a partir da utilização de TICs.

Para tanto, será apresentado, a seguir, para efeito de contextualização, um breve panorama dos resultados da pesquisa TIC Educação 2018 sobre o acesso à Internet de professores e estudantes brasileiros, além da utilização da tecnologia pelos docentes para a realização de atividades escolares. Em seguida, a partir do olhar de dois professores pesquisadores da Rede Municipal de Educação de Quissamã, no litoral norte fluminense, será problematizada a transferência, em caráter excepcional e temporário, das atividades escolares para o ERE durante a pandemia da Covid-19, bem como a importância da continuidade de utilização das TICs como ferramenta de otimização dos processos de ensino-aprendizagem.

\section{Como é o acesso à internet de professores e estudantes no Brasil?}

Tendo como população-alvo todas as escolas urbanas públicas e particulares do Brasil em 2018 (excluídas as federais), a pesquisa TIC Educação 2018 (NIC.BR, 2019) apontou para a universalização do acesso à Internet entre professores e estudantes do país, resultado que foi confirmado mais recentemente por outra pesquisa, chancelada pelo IBGE (Instituto Brasileiro de Geografia e Estatística), através da PNAD (Pesquisa Nacional por Amostra de Domicílio) ${ }^{4}$.

Realizada pelo Centro Regional de Estudos para o Desenvolvimento da Sociedade da Informação (Cetic.br) do Núcleo de Informação e Coordenação do Ponto BR (NIC.br), a pesquisa TIC Educação 2018 confronta a base de dados do Censo Escolar com uma visita presencial a escolas selecionadas dentro de um plano amostral. $O$ foco são os alunos, diretores de escola e a coordenação pedagógica das escolas urbanas que oferecem $\circ 5^{\circ}$ ano e $\circ 9^{\circ}$ ano do Ensino Fundamental, além do $2^{\circ}$ ano do Ensino Médio.

De acordo com a pesquisa mencionada, 100\% dos professores acessaram a Internet, pelo menos uma vez, nos três meses anteriores a coleta de dados (agosto a dezembro de 2018). A maior parte do acesso se deu em casa (99\%), entre professores de 46 anos ou mais (100\%) com renda familiar de mais de 5 salários mínimos (100\%). Os professores que mais acessaram residem nas regiões Sudeste e Nordeste ( $100 \%$ acessaram) e os que menos acessaram moram na região Norte (94\%). Houve acesso igualitário entre os professores das escolas públicas e particulares ( $99 \%$ nos dois casos) e entre aqueles que lecionam Português, Matemática e múltiplas disciplinas nos anos iniciais do Ensino Fundamental

\footnotetext{
${ }^{4}$ A PNAD Contínua TIC 2018 (IBGE, 2019) constatou que, em 2018, a Internet chegou a 79, I\% dos domicílios do país, com $75,0 \%$ da população entre 10 e 13 anos e $87,7 \%$ da população entre 14 e 17 anos se conectando no $4^{\circ}$ trimestre de 2018 , período de referência da pesquisa.
}

Olhar de professor, Ponta Grossa, v. 24, p. 1-10, e-16022.044, 2021.

Disponível em <https://revistas2.uepg.br/index.php/olhardeprofessor> 
(também $99 \%$ nos três casos). Por sua vez, os professores do $9^{\circ}$ ano do Ensino Fundamental acessaram um pouco mais ( $100 \%$ ) que seus pares do $5^{\circ}$ ano do Ensino Fundamental e do $2^{\circ}$ ano do Ensino Médio ( $99 \%$ nos dois últimos casos).

Cerca de $76 \%$ dos professores declararam ter usado a Internet nos três meses anteriores à pesquisa para aprimorar os conhecimentos sobre o uso de tecnologias nos processos de ensinoaprendizagem. Contudo, quando se trata da utilização na prática de ensino, somente uma minoria afirmou ter aplicado essas tecnologias na sala de aula. Na pesquisa TIC Educação 20।8, apenas 19\% dos professores de escolas públicas urbanas declararam usar a Internet com os alunos pelo menos uma vez por semana, enquanto outros 19\% declararam utilizar a conexão à rede somente uma vez por mês e $24 \%$ declararam nunca utilizar a Internet em atividades com os estudantes.

A pesquisa apontou ainda o predomínio das práticas pedagógicas tradicionais: $94 \%$ exigiram exercícios com respostas escritas, $93 \%$ deram aulas expositivas, $91 \%$ pediram trabalhos em grupo, $87 \%$ solicitaram trabalhos de pesquisa escritos e $85 \%$ realizaram a leitura de textos oralizada com os alunos. Já a promoção de debates ou apresentações (78\%), a produção de textos, desenhos ou maquetes (77\%), o trabalho com jogos educativos e aplicativos (45\%) e a elaboração de planilhas e gráficos (44\%), que correspondem a práticas de ensino mais inovadoras, foram menos solicitadas pelos professores.

Quando se trata do uso da Internet para a realização dessas atividades, por sua vez, os percentuais são ainda mais reduzidos: apenas 39\% dos professores declararam utilizar a Internet nas aulas expositivas, $38 \%$ estimularam o uso da rede nos trabalhos de pesquisa escritos, $37 \%$ incentivaram seu uso nos trabalhos em grupo, 33\% permitiram consulta à Internet na realização de exercícios escritos e apenas $24 \%$ incorporaram a rede na leitura de textos com os estudantes. Mesmo na realização das práticas não tradicionais, os percentuais foram muito baixos: $31 \%$ no uso da Internet para a promoção de debates ou apresentações, $30 \%$ na produção de textos, desenhos ou maquetes, $20 \%$ no trabalho com jogos educativos e aplicativos e apenas I $3 \%$ na elaboração de planilhas e gráficos com os alunos.

Por outro lado, a pesquisa ressalta que, possivelmente, os docentes utilizam tecnologias para planejar atividades, expor conteúdos e fazer pesquisas com os estudantes, inclusive utilizando os próprios dispositivos. Entretanto, em função das dificuldades de compartilhamento da rede, essas atividades nem sempre contariam com a participação mais direta dos estudantes, especialmente quando acontecem na sala de aula. Já na outra ponta, no que se refere à conectividade dos alunos das escolas urbanas, a pesquisa apontou que, em 2018, $84 \%$ deles declararam ser usuários de Internet, desigualmente distribuídos entre as regiões do país (74\% no Norte, $80 \%$ no Nordeste, $84 \%$ no CentroOeste, $87 \%$ no Sudeste e $90 \%$ no Sul). 
Um dado que se considera relevante é a queda da presença de computadores na residência dos estudantes, especialmente das escolas particulares. Em 201 I, 56\% dos estudantes possuíam computador de mesa, percentual que diminuiu para $39 \%$ em 2018 . Em relação à presença de computador portátil e tablet, os percentuais de posse em domicílio foram, respectivamente, de $45 \%$ e $35 \%$ naquele ano. Por sua vez, $30 \%$ dos estudantes não possuíam nenhum dos três tipos de dispositivo em suas residências.

Mesmo assim, a presença de computadores nas moradias dos estudantes apresenta diferenças significativas entre alunos de escolas públicas e particulares: enquanto $72 \%$ dos matriculados em escolas particulares possuíam computador portátil, somente $38 \%$ dos estudantes de escolas públicas tinham esse equipamento no domicílio.

É por isso que o acesso à Internet dessa população se dá predominantemente pelo telefone celular: em 2018,97\% dos estudantes de áreas urbanas, com poucas diferenças entre aqueles de escolas públicas e particulares, mencionaram o uso do dispositivo para acesso à rede.

Nesse cenário, é possível sugerir que o país caminha para a universalização do acesso às TICs, encontrando-se, sobretudo a geração jovem, conforme salientado por Regina Novaes (2016), frequentemente mais conectada, independentemente da situação socioeconômica. Tal constatação, num primeiro momento, poderia levar a conclusão de que a migração para ○ ERE, ainda que temporariamente, durante a pandemia da Covid-19, se apresenta como uma operação estrutural de fácil aplicação, na qual a maioria dos estudantes poderia se adaptar, sem grandes prejuízos para a aprendizagem.

No entanto, a experiência desses dois professores pesquisadores indica que, nem sempre, as pesquisas levam em conta as particularidades do acesso à Internet entre os diferentes grupos sociais. Quais segmentos populacionais possuem acesso a uma Internet rápida? Todos os estudantes, tendo acesso à rede, têm as mesmas possibilidades de uso dos aplicativos de aulas on-line ou de baixar vídeos na quantidade necessária? Todos os alunos das escolas públicas dispõem de espaços adequados para a concentração nas aulas via plataformas digitais?

\section{O olhar de dois professores pesquisadores da educação básica}

Tais questionamentos levaram esses dois professores pesquisadores - que atualmente trabalham juntos no CIEP Municipalizado 465 Dr. Amilcar Pereira da Silva, na Rede Municipal de Educação de Quissamã - a refletir sobre diversos problemas referentes à educação, dentre os quais, destacamos aqui, uma premissa essencial que contribui para esse debate: ou seja, as velhas desigualdades sociais que acometem secularmente os processos educacionais no Brasil não 
desaparecem com a transferência automática, ainda que apenas temporária, para ○ ERE, a despeito da universalização estatística do acesso à Internet por professores e estudantes no país.

Justamente, a experiência desses dois profissionais com mais de uma década de atuação no magistério na educação básica permite, no atual cenário de utilização do ERE durante a pandemia da Covid-19, elencar especialmente uma série de problemas que têm feito parte do dia a dia nas escolas, nesse contexto de maior uso da internet como ferramenta de trabalho. Algumas dessas dificuldades estão materializadas, por exemplo: nos empecilhos impostos pelo acesso a uma rede de baixa qualidade, dificultando a visualização de materiais enviados pelos professores; na impossibilidade de acessar vídeos que exigem um maior volume de dados, como os vídeos enviados por WhatsApp (estratégia adotada, por exemplo, na Rede Municipal de Educação de Quissamã) ${ }^{5}$; na impossibilidade de utilização de aplicativos para aulas on-line também pelo acesso restrito a uma comunicação rápida; nas dificuldades financeiras de muitas famílias em adquirir aparelhos de celular; nos problemas para estabelecer uma rotina de estudos e interação virtual com os professores; ou ainda na falta de espaços adequados, dentro das residências dos estudantes, para a concentração nas atividades escolares e no autoestudo.

Todas essas questões explicitam, obviamente, as enormes desigualdades educacionais que estão sendo produzidas pelo ERE no ano letivo de 2020. Contudo, mais do que meramente uma questão de assimetrias de poder econômico que restringem o acesso a aparelhos celulares de última geração, ou ainda à Internet com dados de navegação ilimitados, as disparidades sociais aqui postas revelam uma problemática mais complexa, que sociólogos como Pierre Bourdieu nos ajudam a compreender melhor.

A teoria central de Bourdieu (2015) que analisa as desigualdades educacionais baseia-se no postulado de que as classes sociais não se diferenciam entre si apenas por uma questão de acúmulo de capital financeiro. Outros tipos de capitais se apresentam no jogo das relações de poder, como o capital social e o capital cultural - poderes simbólicos - que constituem a dominação de classes e se impõem no campo da educação como dispositivos de diferenciação que caracterizam as diversas trajetórias escolares.

Essa proposição teórica do sociólogo francês é importante para nos ajudar a entender, por exemplo, o porquê do simples acesso à Internet (mesmo a de boa qualidade) não se traduzir automaticamente em eficiência educacional entre os estudantes de escola pública das classes populares.

\footnotetext{
${ }^{5}$ A estratégia de ERE adotada pela Secretaria Municipal de Educação de Quissamã foi a de estabelecer a interação entre diretores de escola, professores, coordenadores pedagógicos, alunos e pais ou responsáveis através da criação de grupos de WhatsApp, transformados em salas de aula virtuais. Essa foi a forma encontrada pelos gestores educacionais do município para lidar com as dificuldades de acesso à plataformas digitais e, assim, garantir aos alunos o conteúdo de um currículo mínimo a partir de textos, áudios e vídeos produzidos pelos professores.
} 
Por que é tão difícil, nessa perspectiva, manter uma rotina e concentração para a aprendizagem entre os alunos mais pobres, especialmente no contexto de ERE?

Para Bourdieu, tal dificuldade poderia ser explicada pela expropriação de capitais simbólicos da classe dos trabalhadores, em detrimento de grupos sociais mais abastados que, através do acúmulo de capitais social e cultural, agem especificamente na construção de um habitus de estudos com a finalidade de transmitir de geração em geração uma tradição de acúmulo de conhecimentos escolares. Em outras palavras: se, por um lado, estudantes das classes de maior poder econômico dispõem de uma herança cultural baseada no incentivo aos estudos e viabilizada pela disponibilidade de tempo e acúmulos de capitais simbólicos, por outro lado, os estudantes provenientes de famílias de trabalhadores que estão, majoritariamente, na escola pública são privados (na prática) de construírem uma tradição voltada para o conhecimento pedagógico, na medida em que boa parte do seu tempo familiar está voltada para a venda da força de trabalho com a finalidade premente da sobrevivência imediata.

A experiência desses dois professores ajuda a identificar que os estudantes de famílias com menor renda e pais ou responsáveis menos escolarizados não costumam praticar o autoestudo nem construir, fora da sala de aula, uma rotina voltada para atividades escolares. Geralmente, são exatamente esses alunos os que menos se sentem estimulados a ficar em frente ao celular ou ao computador, prestando atenção em vídeos, áudios ou material didático virtual.

Isso acontece porque pouco se constrói, nas famílias com esse perfil, uma tradição de investimento educacional que possa ser passada, como herança cultural, para todos os seus membros. O tempo do trabalho, nessas famílias de trabalhadores, é sempre aquele que se sobressai pela necessidade diária e, para além disso, a concentração para se dedicar às tarefas propostas pela escola quase sempre acaba esbarrando também na falta de estruturas adequadas na própria residência familiar.

É provável, por esse motivo, que a propaganda do Ministério da Educação (MEC), em favor da realização do Exame Nacional do Ensino Médio (ENEM) em novembro de 2020, veiculada ainda na gestão do ministro Abraham Weintraub, não tenha feito muito sentido para grande parte dos estudantes mais pobres. A peça publicitária em defesa da manutenção da data inicial da prova dizia que era preciso estudar "de qualquer jeito" e de "todas as formas" porque a vida não poderia parar. No comercial, apareciam jovens, aparentemente de classe média, com celulares de "ponta", tripé para suporte do aparelho, mesa de estudos com iluminação e um quarto individual com biblioteca no fundo. Ora, com quem dialogaria, afinal, tal mensagem do MEC? Certamente, muito mais com os jovens alunos das classes de maior poder aquisitivo e maior capital cultural, para os quais o argumento apresentado pelo governo tem fundo de coerência. Isso porque a mudança para o ERE não imprimiu exatamente grandes transformações na vida desses estudantes. A disponibilidade de tempo dedicado à leitura e às 
atividades escolares não foi alterada; a preocupação com questões de sobrevivência diária continuou a não existir; o acesso aos equipamentos para a viabilização das aulas remotas foi devidamente providenciado; e o projeto familiar de transmissão e valorização simbólica do conhecimento escolar continuou intacto.

Já para os jovens das classes mais populares, ao contrário, assistir a uma propaganda na qual se sugere estudar por "todos os meios", sem levar em conta a situação dos mais pobres, provavelmente deve ter soado como um mero vazio de significados. Afinal de contas, quantos estudantes de escola pública teriam, de fato, poder aquisitivo para possuir smartphones potentes e com Internet ilimitada de dados? Existem espaços físicos nas residências adequados para se estudar nessa realidade? Existe tempo disponível desprovido de preocupações com a sobrevivência? O que a nossa experiência pessoal como professores pesquisadores da educação básica e da escola pública tem indicado é que a realidade social dos nossos estudantes está bem longe da caricatura bonita do comercial. Não poucas vezes, por exemplo, o celular da família é compartilhado; o acesso às redes de comunicação acontece apenas em determinados momentos do dia; e a casa com pequenos cômodos e sem disponibilidade de quartos individuais praticamente inviabiliza a concentração nas atividades pedagógicas propostas pela escola.

Tal situação de desfavorecimento fica ainda mais evidente quando o contexto social dos estudantes está caracterizado por uma maior vulnerabilidade marcada pela segregação urbana em regiões periféricas de grandes capitais. É o caso, por exemplo, da Maré, maior conjunto de favelas da cidade do Rio de Janeiro e também lugar de atuação de um dos professores aqui em destaque, como educador popular numa instituição não governamental. ${ }^{6}$ Nesse cenário, as dificuldades causadas pelo ERE são potencializadas ainda mais pela situação de desigualdades estruturais vivenciadas pelos alunos. Isso porque, além dos serviços de Internet que já são em grande parte precarizados, ainda precisa-se lidar com questões referentes à violência que afetam seriamente o aspecto físico e psicológico dos estudantes. Entre estas: contextos sociais em que o acesso qualitativo às redes está longe de uma universalização; estruturas físicas para a prática dos estudos que são limitadas pela própria geografia do lugar; e a preocupação com a sobrevivência material, em especial com o trabalho, acima de qualquer necessidade pedagógica - a esse respeito, a busca por trabalho e renda parece uma preocupação que, não poucas vezes, antecede o desejo de permanecer na escola (SILVA, 2019).

\footnotetext{
${ }^{6} \mathrm{~A}$ instituição não governamental em questão é o Centro de Estudos e Ações Solidárias da Maré (CEASM), que atua nessa comunidade do Rio de Janeiro há 23 anos e trabalha sobretudo no campo da educação, com destaque para um pré-vestibular comunitário que atende estudantes do ensino médio que almejam ingressar nas universidades públicas. Para mais informações, consultar Silva (2019).
} 


\section{Em vias de conclusão...}

No campo da educação, a pandemia da Covid-19 trouxe à tona a necessidade de considerar novas questões nos processos de formulação de políticas educacionais. Uma delas, sem dúvidas, passa por melhor qualificar as pesquisas sobre o acesso às tecnologias de informação no Brasil, a fim de apresentar uma coleta de dados com um melhor refinamento sobre a situação do acesso e a qualidade da Internet de cada grupo social que forma a população estudantil do país. Tal detalhamento, dentro das práticas de investigação, tem o potencial de construir diagnósticos mais precisos sobre o panorama educacional e, dessa maneira, fornecer informações mais consolidadas para que gestores em todas as instâncias de poder formulem políticas públicas de alcance mais fidedigno.

Esse cuidado passa, inclusive, por planejar uma realidade educacional no período pós-pandemia que considere a continuidade da utilização das TICs, a partir da experiência atualmente vivenciada ${ }^{7}$, como uma importante ferramenta para a otimização dos processos de ensino-aprendizagem, de modo a beneficiar, inclusive, a população estudantil pertencente às camadas mais pobres da população, além de todo o universo daquela matriculada na escola pública, num contexto de promoção de oportunidades educacionais para todos.

O que verificamos, portanto, a partir de uma experiência profissional é que as desigualdades sociais intensificam as desigualdades educacionais em momentos de interrupção do contato presencial dos estudantes com a escola e com os professores, a exemplo do que vem acontecendo nesse momento de aplicação do ERE em muitas redes de ensino espalhadas pelo país. Nesse cenário, a solução passa, necessariamente, pela realização de um diagnóstico honesto da situação, a partir da coleta de dados confiáveis, pela transparência dos dados e pela formulação de ações que não ignorem o fato de que, para os estudantes das camadas mais pobres, o ano letivo de 2020, atingido pela pandemia da Covid-19, configura-se num ano escolar praticamente perdido.

\section{Referências}

BOURDIEU, P. Escritos de Educação (seleção, organização, introdução e notas). Tradução de Maria Alice Nogueira e Afrânio Catani. Petrópolis, RJ: Vozes, 2015.

CABELLO, P. et al. La inclusión digital de niños y adolescentes chilenos desde la perspectiva de usos y habilidades. In: JIMÉNEZ, E.; GARMENDIA, M.; CASADO, M. A. (coord.). Entre selfies y whatsapps: oportunidades y riesgos para la infancia y la adolescência conectada. España: Gedisa, 2018.

\footnotetext{
${ }^{7}$ Este artigo foi escrito em agosto de 2020, quando as aulas, em praticamente todas as redes de ensino brasileiras, ainda estavam suspensas na modalidade presencial. Naquele momento, as redes de ensino se dividiam entre a suspensão do calendário letivo e a oferta de atividades escolares sob a forma de ERE, em alguns casos até mesmo aulas virtuais.
} 
HODGES, C. et al. The Difference Between Emergency Remote Teaching and Online Learning. Educause Review, Louisville - Colorado, v. 27, 27 mar. 2020. Disponível em: https://er.educause.edu/articles/2020/3/the-difference-between-emergency-remote-teaching-andonline-learning\#fn I. Acesso em: 10 ago. 2020.

IBGE - INSTITUTO BRASILEIRO DE GEOGRAFIA E ESTATÍ́stICA. Pesquisa nacional por amostra de domicílios contínua - Acesso à Internet e à televisão e posse de telefone móvel celular para uso pessoal 2018 (PNAC Contínua TIC 2018). Rio de Janeiro: IBGE, 2019. Disponível em: https://www.ibge.gov.br/estatisticas/sociais/populacao/I 7270-pnad

continua.html?edicao=23205\&t=sobre. Acesso em: 10 jun. 2020.

NIC.BR. NÚCLEO DE INFORMAÇÃO E COORDENAÇÃO DO PONTO BR. TIC educação 20 I8: pesquisa sobre o uso das tecnologias de informação e comunicação nas escolas brasileiras. São Paulo: Comitê Gestor da Internet no Brasil, 2019.

NOVAES, R. Juventude, religiosidade, territórios e redes: reflexões sobre resultados de pesquisas. In: PINHEIRO, D. et al. (org.). Agenda juventude Brasil: leituras sobre uma década de mudanças. Rio de Janeiro: UNIRIO, 2016.

SILVA, H. S. da. A experiência de jovens estudantes do pré-vestibular do centro de estudos e ações solidárias da Maré (CEASM) - Rio de Janeiro: trajetórias escolares, segregação urbana e educação decolonial. 239 f., 2019, (Tese de Doutorado em Educação) - Universidade Federal do Estado do Rio de Janeiro, Rio de Janeiro, 2019.

UNICEF - FONDO DE LAS NACIONES UNIDAS PARA LA INFANCIA. Niños, niñas y adolescentes conectados: Informe Kids On-line Uruguay. Montevideo: Unicef, 2018.

Recebido em: 15 de junho de 2020.

Versão corrigida recebida em: 09 de novembro de 2020.

Aceito em: 09 de novembro de 2020.

Publicado online em: 08 de maio de 2021. 